\title{
Not All Homes Are Safe: Family Violence Following the Onset of the Covid-19 Pandemic
}

\author{
Kelsey J. Drotning ${ }^{1} \cdot$ Long Doan $^{1} \cdot$ Liana C. Sayer $^{1} \cdot$ Jessica N. Fish ${ }^{2} \cdot$ R. Gordon Rinderknecht ${ }^{3}$
}

Accepted: 1 February 2022 / Published online: 22 February 2022

(c) The Author(s), under exclusive licence to Springer Science+Business Media, LLC, part of Springer Nature 2022

\begin{abstract}
Evidence from victim service providers suggests the COVID-19 pandemic led to an increase in family violence. However, empirical evidence has been limited. This study uses novel survey data to investigate the occurrence of family violence during the early months of the COVID-19 pandemic in the United States. Data come from the second wave of the Assessing the Social Consequences of COVID-19 study, an online non-probability sample collected in April and May 2020. Family violence is measured using four variables: any violence, physical violence, verbal abuse, and restricted access. The authors use logistic regression and KHB decomposition to examine the prevalence of family violence during the COVID-19 pandemic. We find that sexual minorities, in particular bisexual people, experienced higher rates of family violence than heterosexual respondents. Women were the only group to report an increase in the frequency of family violence. Household income loss is associated with the incidence of verbal violence. Our findings demonstrate the importance of expanding victim services to address the additional barriers victims face within the pandemic context and beyond, including broad contexts of social isolation and financial precarity experienced by individuals at risk of family violence.
\end{abstract}

Keywords Family violence $\cdot$ COVID-19 pandemic $\cdot$ Gender $\cdot$ Sexual identity $\cdot$ Family stress theory

\section{Introduction}

Family and victim services professionals have expressed concern that stay-at-home orders and social distancing conditions instituted during the COVID-19 pandemic are exacerbating family violence (Peterman et al., 2020). We define family violence as verbal abuse, physical abuse, or restriction of access to a cell phone or the internet, perpetrated by a member of the household against another member of the

Kelsey J. Drotning

kdrotnin@terpmail.umd.edu

1 Department of Sociology, Univeristy of Maryland, 2112 Parren Mitchell Art-Sociology Building, 3834 Campus Dr., College Park, MD 20742, USA

2 School of Public Health, University of Maryland, College Park, MD, USA

3 Max Planck Institute for Demographic Research, Rostock, Germany household. ${ }^{1}$ There are some indications that the pandemic has led to an increase in family violence. In the United States, contact volume at the National Domestic Violence Hotline was 15 percent higher in April 2020 than in April 2019 (National Domestic Violence Hotline [NDVH], 2020). Both China and Australia have reported higher than average police reports of intimate partner violence and calls for help since the start of the pandemic (Lattouf, 2020; Wanqing, 2020). Additionally, a study of women in Spain found a 23 percent increase in intimate partner violence following the country's three-month lockdown at the onset of the pandemic (Arenas-Arroyo et al., 2021).

Although research on the association between pandemics and family violence is scarce, numerous studies

\footnotetext{
$\overline{1}$ This paper focuses on violence perpetrated against people over the age of 18 . While family violence includes child abuse, intimate partner violence, elder abuse, and abuse against others in the same household, our sample is limited to those 18 years of age and older and cannot draw conclusions about elder abuse due to limited sample size of $60+$.
} 
indicate family violence increases in crisis settings characterized by duress, social isolation, and financial strain for long periods of time (Peterman et al., 2020; Wako et al., 2015). There is emerging evidence lockdowns are associated with an increase in psychological intimate partner violence (Arenas-Arroyo et al., 2021). Previous research has also established economic and financial strain, which has accompanied the COVID-19 pandemic, as a predictor of family violence (Anderberg et al., 2016; Fox et al., 2002; Renzetti, 2009). To support families, it is vital that we understand how the pandemic has changed the occurrence of violence in households. This study uses novel data from the Assessing the Social Consequences of COVID-19 study (ASCC), to document if and how known risk factors for family violence and experiences of household income loss following the onset of the pandemic are associated with rates of family violence. We motivate our study by synthesizing current knowledge about risk factors for family violence against adults prior to and during the COVID19 pandemic and discuss how these may be exacerbated by the pandemic.

\section{Family Violence in the United States}

In $2019,4.2$ per 1,000 people aged 12 or older were victims of family violence in the United States, and 60 percent of victims reported intimate partner violence specifically (Morgan \& Truman, 2020). Estimates from the National Intimate Partner and Sexual Violence Survey indicate that a third of women and men will experience sexual violence, physical violence, and/or stalking perpetrated by an intimate partner during their lifetime. Despite similar rates of total victimization, 1 in 4 women who report intimate partner violence in their lifetime also experience an IPV related impact (concern for safety, absence from school or work, injury, etc.) compared to 1 in 10 men. Women also report higher rates of severe physical violence, stalking, and sexual violence than men (Smith et al., 2018).

Sexual and racial minorities, immigrants, disabled persons, and other marginalized populations have higher rates of victimization and face additional barriers to seeking safety than other groups (Breiding et al., 2014; McGeough \& Sterzing, 2018; Walters et al., 2013). The lifetime prevalence of intimate partner violence is higher for most sexual minorities with 44 percent of lesbian women, 61 percent of bisexual women, 26 percent of gay men, and 38 percent of bisexual men expected to experience intimate partner violence in their lifetime compared to 35 percent of heterosexual women and 29 percent of heterosexual men (Walters et al., 2013). Lifetime prevalence of intimate partner violence is higher for women of color with 46 percent of Native American women, 44 percent of Black women, and 37 percent of Hispanic women expected to experience intimate partner violence in their lifetime compared to 35 percent of white women. Although overall rates of family violence are lower among immigrants, immigrants face additional vulnerabilities because of their legal status and unfamiliarity with U.S. family law (Curry et al., 2018; Zadnik et al., 2014).

While we have good estimates of family violence before the COVID-19 pandemic, estimates of how family violence has changed following the onset of the pandemic are lacking. Between March 16 and May 16, 2020, the National Domestic Violence Hotline (2020) saw a 9 percent increase in contacts to the hotline compared to the prior year. Most contacts to the hotline describe experiencing emotional and verbal abuse, followed by financial and economic abuse. Importantly, 10 percent of contacts to the hotline cited abuse specific to the COVID-19 pandemic (NDVH, 2020). Some survivors have reported being prevented from contacting their family and friends to notify them of a positive test. Others described their partner providing false information regarding quarantine protocols (NDVH, 2020; Usher et al., 2020). Although there is some anecdotal evidence of increasing family violence in the United States following the onset of the COVID-19 pandemic, national level survey data is lacking.

\section{Family Violence During a Pandemic}

Previous research has documented increases in family violence following natural disasters (Gearhart et al., 2018; Rezaeian, 2013) and economic crises (Brooks-Gunn et al., 2013; Culley \& Sanders, 2010; Renzetti, 2009; Schneider et al., 2016). Social isolation, including limited contact with family and friends or others outside the household, is also a risk factor (Lanier \& Maume, 2009; Stark, 2007). This suggests that extreme social isolation from pandemic stay-at-home orders (Usher et al., 2020), and the resulting economic recession (Prime et al., 2020) should lead to an increase in family violence (Peterman et al., 2020; Zhang, 2020).

The Family Stress Model suggests that both perceived and actual economic hardship increase stress related to meeting basic family needs and financial obligations, which may lead to emotional distress and the perpetration of family violence (Conger et al., 1990, 2000). In a test of the Family Stress Model, Fox and colleagues (Fox et al., 2002) found that actual economic conditions within a family are an important predictor of intimate partner violence, after controlling for experiences of previous violence. They also found that when one or both partners have 
a negative perception of their own financial well-being, there is a higher risk of violence within the relationship (Fox et al., 2002). In a study using data from the Fragile Families and Child Well-Being Study, Lucero et al. (2016) found that familial economic instability was associated with experiencing intimate partner violence, mediated by parental stress.

Economic recessions also contribute to perceived and actual financial strain and family stress. Previous research has shown increased family violence is associated with periods of macrolevel economic strain, regardless of actual financial hardship within the family (Brooks-Gunn et al., 2013; Culley \& Sanders, 2010; Renzetti, 2009; Schneider et al., 2016). Following the onset of the 2008 recession, calls to domestic violence organizations increased (Renzetti, 2009). In a study of intimate partner violence during the 2008 recession, Schneider et al. (2016) show an increase in men's controlling and verbally abusive behavior toward their spouse or partner is directly tied to economic uncertainty, even after controlling for individual hardship. Interestingly, they did not find an increase in physical abuse (Schneider et al., 2016). Similarly, a study of women in Spain during the early months of the COVID-19 pandemic found an association between the pandemic and an increase in psychological violence, even after controlling for economic loss (ArenasArroyo et al., 2021).

The COVID-19 pandemic has increased actual and perceived economic strain, increasing family stress, though this varies by family demographics and work arrangements. Although about 30 percent of the American workforce was able to work from home before the pandemic, this was concentrated among more educated predominantly white workers. Only 16 percent of Hispanic workers and 20 percent of Black workers could telework, increasing their risk of job loss or exposure to COVID19 (Gould \& Shierholz, 2020). Furthermore, women are disproportionately concentrated in low-wage service or health jobs. During the pandemic, workers in these types of jobs lost their jobs at high rates and for remaining workers required on-site work (Bateman \& Ross, 2020). Mothers who remained employed reduced job hours or voluntarily left jobs due to the lack of childcare following pandemic-related closures of care facilities. This loss of hours was particularly high for women of color, without a college degree, and living in low-income households (Modestino, 2020). Research has also shown LGBTQ identified workers are more likely than heterosexual workers to be employed industries highly affected by COVID-19, increasing risk of abuse (Whittington et al., 2020). People who identify as LGBTQ may also have to live with or spend additional time with people who are causing them harm during the pandemic, rely on abusive persons for financial assistance, and be unable to access needed services, further compounding their risk (Dixon, 2020; Fish et al. 2021; Salerno et al., 2021). Finally, loss of income is an additional barrier to seeking safety and relief from abuse (Renzetti, 2009).

In this study, we provide new knowledge on how the pandemic has affected the experience of family violence for U.S. adults. Based on prior work and social services data collected during the pandemic, we anticipate that family violence will have increased during the pandemic, that increases will be larger for women, racial minorities, and sexual minorities. Women and sexual minority identified workers are least likely to be able to telework and at greater risk of job loss, factors that should increase family stress and risk of family violence. We also anticipate that increases will be limited to or more pronounced for verbal and emotional violence compared with physical violence. The results of our study inform the larger literature on risk factors for family violence, specifically experiences of social isolation and economic strain.

\section{Methods and Data}

The data are from the multi-wave Assessing the Social Consequences of COVID-19 (ASCC) study. ASCC is part of a larger project designed to collect information on social behaviors, attitudes, health, and time use before, during, and after the COVID-19 pandemic in the United States. This paper uses data from the second wave of data collection, obtained between April 7 to May 15, 2020. Questions regarding family violence were not included in the first wave of the study. The analytic sample includes 2,891 respondents who provided complete data on all variables used in this analysis. ${ }^{2}$ Respondents were recruited online using Prolific and MTurk and lived in all regions of the United States. Respondents were paid $\$ 2.50$ for completing the survey portion of the study and an additional $\$ 4.50$ for completing a time diary.

Prolific and MTurk are crowdsourcing platforms used by scholars, among others, to recruit participants for online studies. Crowdsourcing platforms reduce the cost of conducting large sample surveys across a large geographic area, increasing research efficiency (Goodman \& Paolacci, 2017). We limit the effects of self-selection by providing only a basic description of the nature of the study to participants and documenting sample demographics (Hauser et al., 2019). Both platforms have been found to produce high quality data using traditional metrics such as satisficing

\footnotetext{
$\overline{2}$ Specification checks using multiple imputation does not produce substantively different results to those presented.
} 
Table 1 Family violence survey questions

$\begin{aligned} & \text { Physical abuse } \\ & \text { During the past seven days, has someone who lives with you slapped, punched, hit, kicked, pushed, or forced you to do } \\ & \text { something sexually that you didn't want to do? }\end{aligned}$
$\begin{aligned} & \text { Vuring the past seven days, has someone who lives with you threatened you or called you fat, ugly, or a hurtful name? } \\ & \text { Restricted access }\end{aligned} \quad \begin{gathered}\text { During the past seven days, has someone who lives with you demanded access to your cell phone, email, or social media } \\ \text { accounts? }\end{gathered}$
Change
Has this increased, decreased or stayed about the same since the novel coronavirus/COVID-19?

and attention checks, ${ }^{3}$ participant naivety, and the sample's ability to reproduce well-documented effects in prior studies (Peer et al., 2017). We ensure high data quality by requiring positive reputations ${ }^{4}$ (Peer et al., 2014) and by following procedures for excluding VPS users ${ }^{5}$ (Winter et al., 2019). The ASCC was approved by the University of Maryland Institutional Review Board (IRBNetID: 1,589,068).

\section{Dependent Variables}

There are five dependent variables in this analysis: physical violence, verbal abuse, restricted access, any family violence, and change in family violence. Participants in the ASCC who stated they did not live alone were asked if they had experienced three types of family violence in the preceding seven days: physical abuse, verbal abuse, and restriction of access to communication devices (see Table 1). These items are a sub-set of items in the Intimate Partner Violence - Gay and Bisexual Men scale (IPVGBM). The IPV-GBM scale was adapted from a general populations scale (Revised Conflict Tactics Scale) and consists of five factors made up of 23 items (Stephenson \& Finneran, 2013). Because the ASCC survey covered a wide variety of topics and was long, to reduce respondent burden, we condensed three of the IPV-GBM factors (physical and sexual IPV, emotional IPV, and monitoring behaviors) into one question each. We removed gender and sexual identity specific language for broader applicability, but kept the same factors (excluding HIV), to capture the experiences of sexual minorities and gay men in particular.

\footnotetext{
3 Attention check questions (ACQs) are used to flag respondents who are not paying attention to the survey. These may be trick questions or questions with very specific instructions about how to answer. ACQ's have been shown to increase data quality by allowing the removal of inattentive respondents (Peer, Vosgerau, and Acquisti 2014).

${ }^{4}$ Survey platforms like Prolific and MTurk allows researchers to reject or accept a respondents survey response. A respondent's "reputation" reflects the percentage of surveys that have been accepted. Researchers can set a minimum qualification (i.e., $95 \%$ of previous submissions were approved) for respondents to be eligible to participate in their survey (Peer, Vosgerau, and Acquisti 2014).

${ }^{5}$ VPS users are online survey respondents who hide their location using a Virtual Private Server (VPS) or Virtual Private Network (VPN) (Winter et al., 2019).
}

Any violence is a binary variable to indicate if a respondent answered yes to at least one of the family violence measures. We also asked respondents if the level of violence they experienced in the previous 7 days had decreased, stayed the same, or increased compared to prior to onset of the COVID-19 pandemic (March 1, 2020). Change is a binary variable that indicates the level of family violence increased. Respondents who said family violence had decreased or stayed the same were grouped together due to the small number of people who reported family violence decreased ( $n=18$ out of 2,891 respondents).

\section{Independent Variables}

To understand the impact of the COVID-19 linked economic recession on family violence in the United States, respondents reported how their household income changed following the onset of the pandemic. Income change is a binary dummy variable to indicate if the respondent's household income decreased following the onset of the pandemic. Due to the small number of people who reported their income increased who also experienced any family violence $(n=23)$, respondents whose income increased and whose income stayed the same have been grouped together. We include household income as a control. We code into a three-category variable based on yearly household income: less than $\$ 35,000$ a year, $\$ 35,000$ to 75,000 , and $\$ 75,000$ or more.

We asked participants to report both sex at birth and their gender identity. Because the number of participants who reported a different sex at birth from their current gender identity was small, we chose to use gender identity to portray each respondent's current identification more accurately. Men are coded as $0(n=1,217)$ and women are coded as $1(n=1,674)$ Respondents who stated their gender as "other" were removed from the sample due to small sample sizes $(n=36)$. Sexual identity is a three-category variable that includes bisexual $(n=309)$, heterosexual $(n=2,401)$, and combines lesbian/gay $(n=105)$ and other sexual identity $(n=76)$ into one group to maximize sample size. We do not include race and ethnicity as focal variables in this analysis because variation in family violence across racial-ethnic groups was not statistically significantly different. 


\section{Control Variables}

We include several control variables that have been identified in the literature as being related to family violence (Smith et al., 2018). Race/ethnicity is a mutually exclusive fivecategory variable which includes white $(n=1,916)$, Latinx $(n=191)$, Black $(n=191)$, Asian $(n=324)$, and other $(n=269)$. The "other" category includes individuals who identified their race as American Indian or Alaska Native, Middle Eastern or North African, Native Hawaiian or other Pacific Islander, some other race, and those who selected multiple categories. We collapse these groups into one heterogeneous group because of low sample size. Age is a continuous variable ranging from age 18 to 80 .

We did not ask respondents to disclose who specifically perpetrated violence against them; however, we did ask who else lived in the household which we used to construct a mutually exclusive categorical variable of household composition with the following categories: partner only $(n=760)$, partner and children $(n=657)$, partner and other $(n=200)$, parents and/or siblings $(n=847)$, and other $(n=427)$. The other category captures respondents who live in homes with friends, roommates, or a combination of the other categories.

\section{Analysis Strategy}

We begin by exploring experiences with different types and changes in the level of family violence during the COVID-19 pandemic by income change, gender, and sexual identity. Second, to assess whether household income loss mediates the relationship between gender, sexual identity, and experiences with family violence, we employ the KHB decomposition method (Breen et al., 2013). We present models regressing gender, sexual identity, and our control variables on each type of family violence, with and without income change. Finally, we examine how each type and changes in level of family violence vary by gender and sexuality by presenting predicted probabilities from the full logistic regression models. All models were estimated using robust standard errors and the analysis was conducted using Stata 15.

\section{Findings}

Table 2 presents sample characteristics by gender. Respondents lived with at least one other person at the time of the survey and were over the age of 18 (see Table 1). Men were 42.1 percent of the sample $(n=1,217)$ and women were 57.9 percent $(n=1,674)$ of the sample. Most of the sample identified as heterosexual (83.1 percent), white (66.3 percent), and had a household income greater than $\$ 75,000$ a year (41.9 percent). Living arrangements
Table 2 Sample statistics by gender

\begin{tabular}{|c|c|c|c|}
\hline & $\begin{array}{l}\text { All } \\
(n=2,891) \\
\% / \mathrm{M}(\mathrm{SD})\end{array}$ & $\begin{array}{l}\text { Men } \\
(n=1,217) \\
\% / \mathrm{M}(\mathrm{SD})\end{array}$ & $\begin{array}{l}\text { Women } \\
(n=1,674) \\
\% / \mathrm{M}(\mathrm{SD})\end{array}$ \\
\hline Income loss & 43.38 & 41.99 & 44.38 \\
\hline \multicolumn{4}{|l|}{ Sexual Identity } \\
\hline Lesbian/Gay/Other & 6.26 & 5.18 & 7.05 \\
\hline Bisexual & 10.69 & 5.51 & 14.46 \\
\hline Heterosexual & 83.05 & 89.32 & 78.49 \\
\hline \multicolumn{4}{|l|}{ Race/Ethnicity } \\
\hline White & 66.27 & 64.59 & 67.5 \\
\hline Latinx & 6.61 & 6.90 & 6.39 \\
\hline Black & 6.361 & 6.00 & 7.05 \\
\hline Asian & 11.21 & 13.56 & 9.5 \\
\hline Other & 9.30 & 8.96 & 9.56 \\
\hline \multicolumn{4}{|l|}{ HH income } \\
\hline Lower than $35 \mathrm{k}$ & 24.70 & 21.94 & 26.7 \\
\hline $35 \mathrm{k}-75 \mathrm{k}$ & 33.41 & 32.87 & 33.81 \\
\hline $75 \mathrm{k}$ or higher & 41.89 & 45.19 & 39.49 \\
\hline \multicolumn{4}{|l|}{ Lives with } \\
\hline Partner only & 26.29 & 23.58 & 28.26 \\
\hline Partner and children & 22.73 & 20.87 & 24.07 \\
\hline Partner and other & 6.92 & 6.90 & 6.93 \\
\hline $\begin{array}{l}\text { Parents and/or } \\
\text { siblings }\end{array}$ & 29.30 & 35.83 & 24.55 \\
\hline Other & 14.77 & 12.82 & 16.19 \\
\hline Age & $32.56(11.25)$ & $31.32(10.26)$ & $33.46(11.85)$ \\
\hline
\end{tabular}

Table 3 Bivariate associations of income change, gender, and sexuality with type of family violence experienced $(n=2,891)$

\begin{tabular}{lclll}
\hline & Any & Physical & Verbal & Access \\
\hline All & 7.09 & 1.83 & 5.60 & 2.35 \\
Income change & & & & \\
$\quad$ Stayed the same or increased & 5.26 & 1.53 & 4.28 & 1.89 \\
$\quad$ Decreased & 9.49 & 2.23 & 7.34 & 2.96 \\
Gender & & & & \\
$\quad$ Men & 7.40 & 2.46 & 5.01 & 3.86 \\
$\quad$ Women & 6.87 & 1.37 & 6.03 & 1.25 \\
Sexuality identity & & & & \\
$\quad$ Lesbian/Gay/Other & 10.50 & 4.97 & 9.94 & 4.42 \\
$\quad$ Bisexual & 12.61 & 2.91 & 9.39 & 4.85 \\
$\quad$ Heterosexual & 6.12 & 1.46 & 4.79 & 1.87 \\
\hline$\quad$
\end{tabular}

were varied, with 26.3 percent of respondents reported living with only a partner, 22.7 percent reporting they lived with a partner and children, and 29.3 percent reporting they lived with their parents and/or siblings. Slightly less than half of respondents reported their income decreased (43.4 percent). 
Table 4 Bivariate associations of income change, gender, and sexuality with increased family violence $(n=202)$

\begin{tabular}{lc}
\hline & Increased \\
\hline All & 46.04 \\
Income change & \\
$\quad$ Stayed the same or increased & 36.90 \\
$\quad$ Decreased & 52.54 \\
Gender & \\
$\quad$ Men & 37.50 \\
$\quad$ Women & 52.63 \\
Sexual identity & \\
$\quad$ Lesbian/Gay/Other & 42.11 \\
$\quad$ Bisexual & 51.28 \\
$\quad$ Heterosexual & 45.14 \\
\hline
\end{tabular}

\section{Prevalence of Family Violence During the COVID-19 Pandemic}

Table 3 presents descriptive statistics by type of violence experienced by our variables of interest: income loss, gender, and sexuality. Respondents whose household income decreased, and sexual minorities reported higher rates of violence than other groups. Overall, 7.1 percent of the sample experienced any family violence in the preceding 7 days. Verbal abuse (5.6 percent) was the most common type of family violence experienced by respondents, followed by restricted access (2.4 percent), and physical violence (1.8 percent). These rates are higher than the estimated prevalence in 2019 (Morgan \& Truman, 2020). Surprisingly, men reported higher rates of any family violence than women, 7.4 percent, and 6.9 percent respectively, though the difference is not significant. Sexual minorities reported higher rates of violence than heterosexual people across all types of violence. Relative to 6.1 percent of heterosexual respondents, 12.6 percent of bisexual people and 10.5 percent of lesbian/ gay/other people reported experiencing any family violence. Table 4 presents descriptive statistics of people in the sample who said yes to at least one of the three family violence measures $(n=202)$. Overall, 46.0 percent of respondents reported the level of violence they experienced increased. Individuals who reported their income had decreased experienced larger increases. Over half of women and bisexual participants reported an increase in family violence.

\section{Family Stress During the COVID-19 Pandemic}

The first step of the mediation analysis (see Appendix 1) shows income loss may be a mediator for the differences between bisexual people experiencing family violence and other groups. Bisexual people had higher odds of experiencing household income loss than heterosexual and gay/ lesbian/other people. Household income loss is also associated with experiencing any family violence and verbal abuse.

Table 5 Odds Ratios from multivariate logistic regressions of experiences of family violence during the COVID-19 pandemic $(n=2,725)$

\begin{tabular}{|c|c|c|c|c|c|c|c|c|}
\hline & \multicolumn{2}{|c|}{ Any violence } & \multicolumn{2}{|l|}{ Physical } & \multicolumn{2}{|l|}{ Verbal } & \multicolumn{2}{|c|}{ Restricted access } \\
\hline & Model 1 & Model 2 & Model 3 & Model 4 & Model 5 & Model 6 & Model 7 & Model 8 \\
\hline Income Loss & & $1.68 * *$ & & 1.38 & & $1.61 * *$ & & 1.33 \\
\hline Women (Ref: Men) & 0.88 & 0.88 & $0.49 *$ & $0.49 *$ & 1.23 & 1.24 & $0.25 * * *$ & $0.25 * * *$ \\
\hline \multicolumn{9}{|c|}{ Sexual Identity (Ref: heterosexual) } \\
\hline Lesbian/Gay/Other & 1.57 & 1.57 & $3.88 * *$ & $3.87 * *$ & $1.83 *$ & $1.83 *$ & $2.92 *$ & $2.90 *$ \\
\hline Bisexual & $1.95 * *$ & $1.90 * *$ & 2.10 & 2.06 & $1.74 *$ & $1.70 *$ & $3.55^{* * *}$ & $3.47 * * *$ \\
\hline \multicolumn{9}{|l|}{ Race/Ethnicity (Ref: white) } \\
\hline Latinx & 1.36 & 1.28 & 0.83 & 0.81 & 1.35 & 1.28 & 1.61 & 1.56 \\
\hline Black & 1.07 & 1.06 & 1.30 & 1.31 & 0.83 & 0.83 & 1.65 & 1.65 \\
\hline Asian & 0.89 & 0.87 & 1.17 & 1.16 & 0.81 & 0.80 & 1.39 & 1.37 \\
\hline Other & 1.42 & 1.39 & 1.63 & 1.62 & 1.28 & 1.25 & 0.97 & 0.96 \\
\hline \multicolumn{9}{|c|}{ HH income (Ref: 75 k or higher) } \\
\hline Lower than $35 \mathrm{k}$ & 1.44 & 1.33 & 1.16 & 1.09 & 1.06 & 0.98 & 1.45 & 1.36 \\
\hline $35 \mathrm{k}-75 \mathrm{k}$ & 1.34 & 1.24 & 0.67 & 0.63 & 1.14 & 1.06 & 1.09 & 1.03 \\
\hline \multicolumn{9}{|l|}{ Lives with } \\
\hline Partner and children & 1.53 & 1.51 & 2.54 & 2.51 & 1.47 & 1.46 & $2.89 *$ & $2.85^{*}$ \\
\hline Partner and other & $2.74 * *$ & $2.54 * *$ & $4.82 * *$ & $4.59 * *$ & $4.00 * * *$ & $3.77 * * *$ & $5.60 * * *$ & $5.35 * * *$ \\
\hline Parents and/or siblings & $2.13 * *$ & $2.08 * *$ & 1.83 & 1.81 & $3.13 * * *$ & $3.08 * * *$ & 1.57 & 1.54 \\
\hline Other & 1.42 & 1.38 & 0.90 & 0.88 & 1.71 & 1.67 & 1.47 & 1.44 \\
\hline Age & 0.99 & 0.99 & 0.98 & 0.98 & 1.00 & 1.00 & 0.98 & 0.98 \\
\hline
\end{tabular}


Fig. 1 Predicted probability of experiencing any family violence by gender and sexual identity

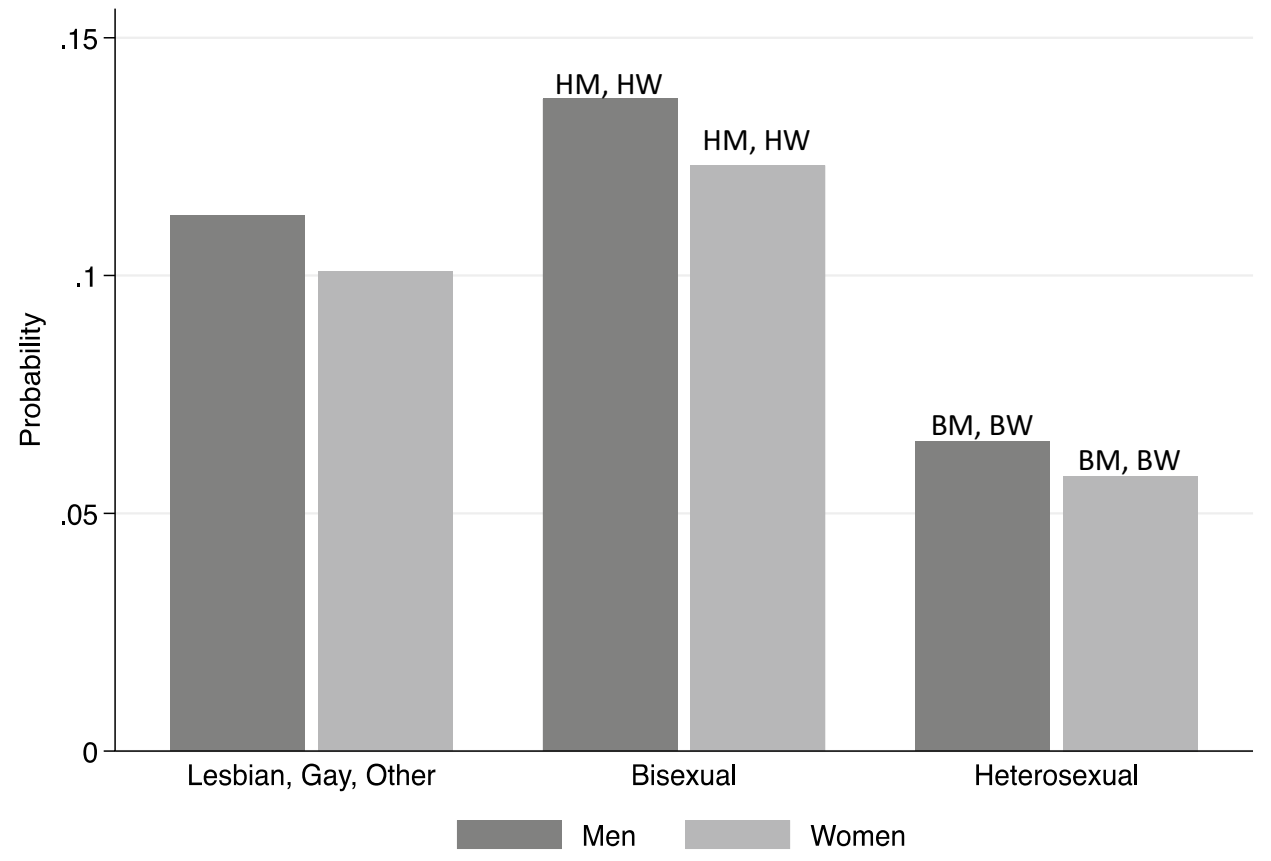

Note: Predicted probabilities from Model 2. Subscripts show the group differs from indicated groups at $p<0.5$. $H M=$ heterosexual men, $H W=$ heterosexual women, $B M=$ bisexual men, $B W=$ bisexual women.
Therefore, we use the KHB decomposition to test for this possibility. However, the KHB decomposition shows that household income loss is not a significant mediator.

Table 5 presents the results of logistic regression models testing the association between household income loss and family violence net of control variables. Our results suggest the COVID-19 pandemic and concurrent economic recession is associated with experiencing family violence, particularly verbal abuse. Household income loss is associated with experiencing any family violence and verbal abuse but is not associated with experiencing physical violence or restricted access.

\section{Gender, Sexual Identity, and Family Violence}

Figure 1 presents the predicted probability of experiencing any family violence by gender and sexual identity. Sexual minorities are more likely to experience all types of family violence than heterosexual people. Bisexual men and women had a higher probability of experiencing family
Fig. 2 Predicted probability of experiencing physical violence by gender and sexual identity

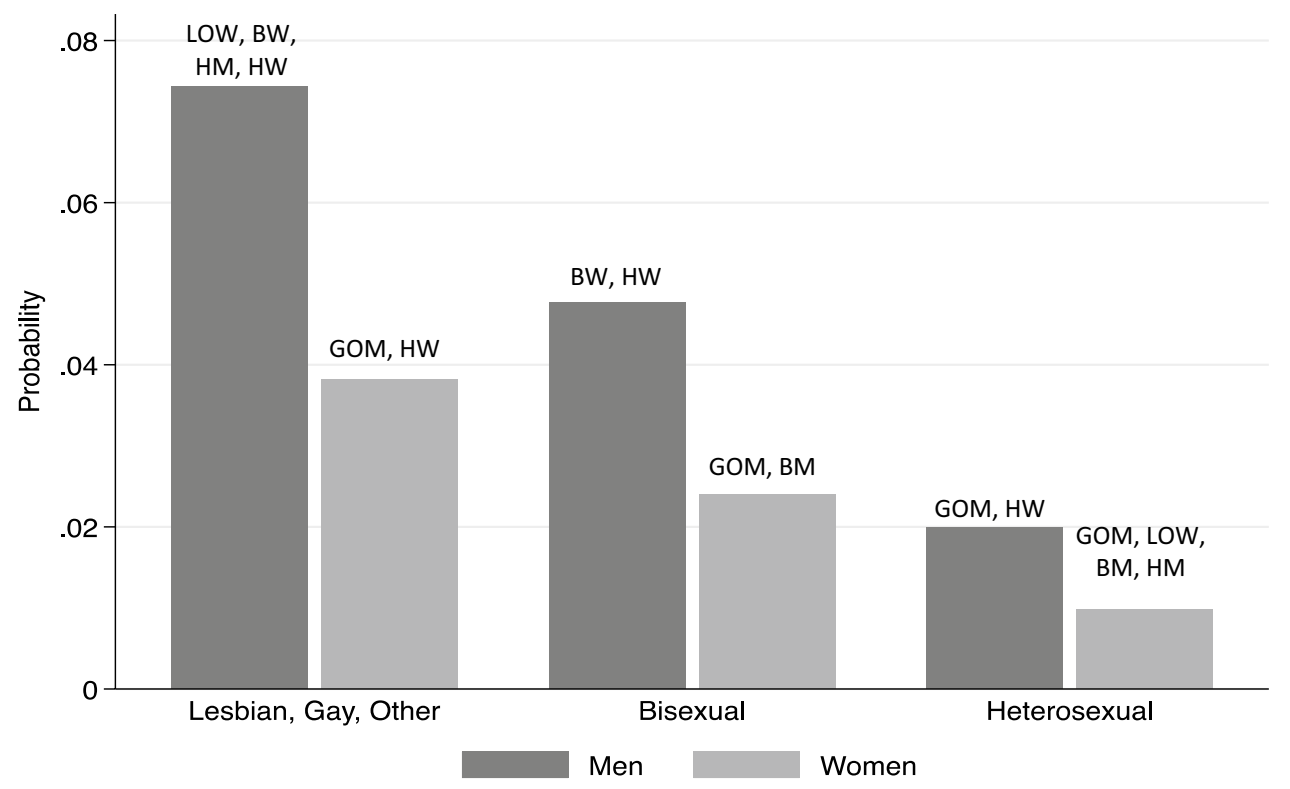


Fig. 3 Predicted probability of experiencing verbal abuse by gender and sexual identity
Fig. 4 Predicted probability of experiencing restricted access by gender and sexual identity
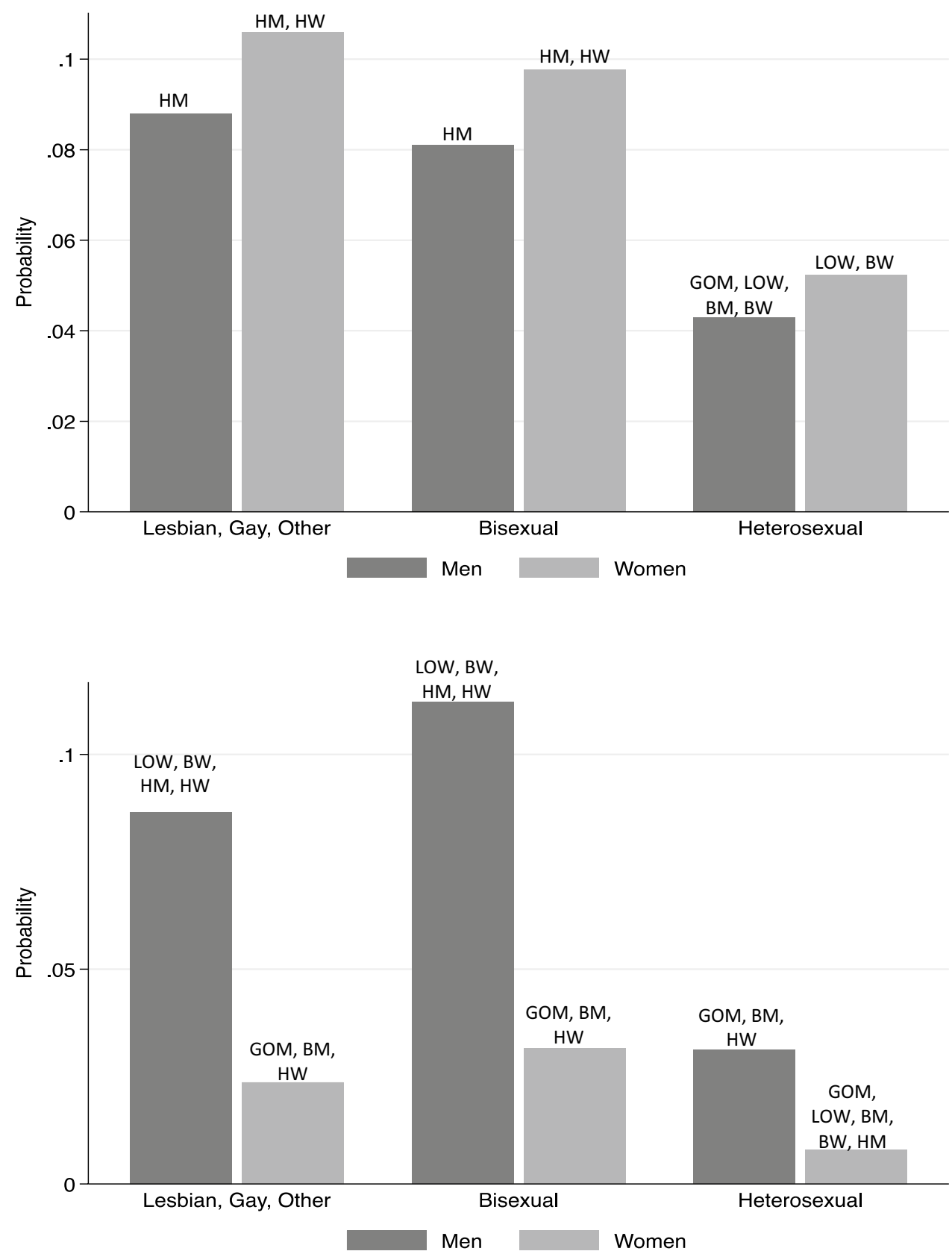

violence than heterosexual men and women. Figures 2, 3, and 4 show predicted probability of experiencing physical violence, verbal abuse, and restricted access by gender and sexual identity. Gay and other men have the highest probability of experiencing physical violence ( 7.5 percent). This is significantly higher than the probability of experiencing physical violence among all women and heterosexual men. Heterosexual women have the lowest probability of experiencing physical violence ( 1.0 percent), though this does not significantly differ from bisexual women (2.4 percent).

Women have a higher probability of experiencing verbal abuse than men. Except for heterosexual women, all groups have a higher probability of experiencing verbal abuse than heterosexual men (Fig. 3). Lesbian, other (10.6 percent), and bisexual women ( 9.8 percent) are significantly more likely to experience verbal abuse than heterosexual women (5.2 percent). All groups are more likely to experience restricted access than heterosexual women (Fig. 4). Bisexual men have the highest predicted probability of experiencing restricted access (11.2 percent) followed by Gay and Other men ( 8.7 percent). Our results suggest that sexual minorities are particularly vulnerable to experiencing family violence during the COVID-19 pandemic.

Figure 5 presents the predicted probability of experiencing an increase in family violence after adjusting for 
Fig. 5 Predicted probability of experiencing an increase in family violence by gender and sexual identity

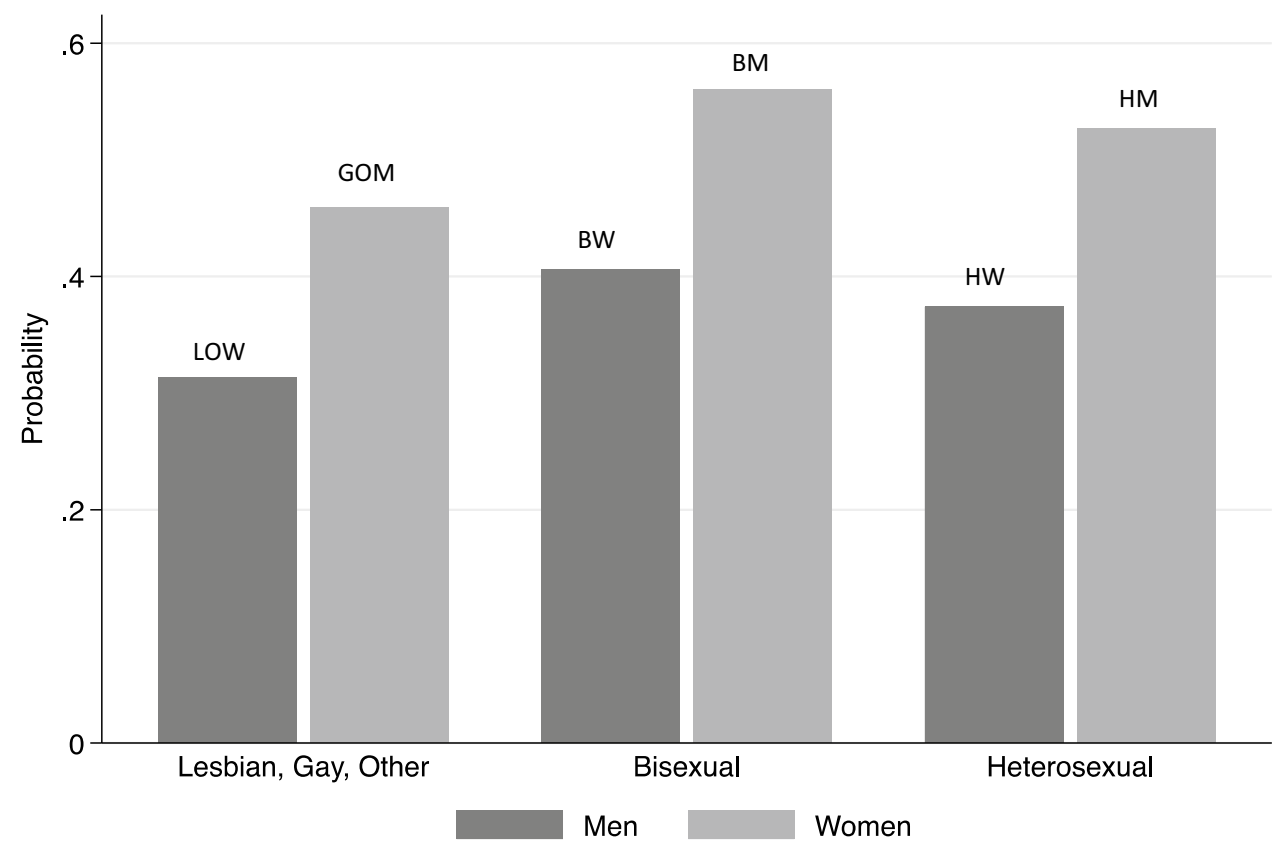

household income loss, gender, and sexual identity (see Appendix 2). Household income loss is associated with an increase in the odds of increased family violence $(p<0.05)$. Within sexual identity groups, women have a higher probability of reporting an increase in family violence than men. Our results indicate that while sexual minority groups have a higher prevalence of family violence during the pandemic, women have experienced an increase in the level of family violence.

\section{Discussion}

This study contributes to the growing body of evidence that the COVID-19 pandemic has led to an increase in family violence. The COVID-19 pandemic increased economic strain and family stress through job loss, decreased hours, and shifts to telework. Parents had to negotiate closed schools and childcare centers, with mothers often reducing hours or leaving their jobs (Bateman \& Ross, 2020). Findings from our study support the Family Stress Model (Conger et al., 1990). Respondents whose household income decreased following the onset of the pandemic were nearly twice as likely to experience an increase in the frequency of family violence, even after controlling for gender and sexual identity. This suggests that in households where family violence occurred pre-COVID-19, deteriorating economic conditions increased family stress, leading to greater family violence.

Respondents whose household income decreased following the onset of the pandemic were also more likely to experience verbal abuse than respondents whose household income did not decrease. This finding aligns with other research from the COVID-19 pandemic in Spain, which found an increase in the number of women experiencing psychological abuse (Arenas-Arroyo et al., 2021). Additionally, research on family violence during the Great Recession indicated an increase in verbal abuse, but not physical violence following increased economic hardship (Schneider et al., 2016). It is possible that in homes where family violence is not a regular occurrence, increased family stress is leading to greater verbal abuse, but not physical or other types of abuse.

Although our study captures the effects of income loss on family violence overall, it also points to the particular vulnerability of young adults. The pandemic has intensified the decades-long trend of increasing economic precarity among young adults who haven't been able to build the same financial independence as their parents, leaving them more vulnerable to economic stress (Kalleberg \& Vallas, 2018; Ruggles, 2015). Young adults have experienced job loss and wage reductions at higher rates than other groups, increasing their likelihood of moving in with parents, and exposing them to potential abuse (Fry et al., 2020). Other COVID-19 related research has found that women and mothers are disproportionately responsible for adjusting their schedules and limiting paid employment to account for childcare responsibilities (Calarco et al., 2021). For some couples, this has led to greater conflict during the pandemic, particularly among couples with small children (Calarco et al., 2020). Our study may be capturing some of this dynamic as respondents who lived with their parents and/or siblings had higher odds of experiencing family violence than partner only households.

Our study supports previous research suggesting people who identify as gay, lesbian, bisexual, or another sexual identity have higher rates of family violence than people who identify 
as heterosexual (McGeough \& Sterzing, 2018; Tillery et al., 2018; Walters et al., 2013). In our study, 33.3 percent of bisexual respondents and 42.0 percent of lesbian, gay, and other sexuality respondents reported living with parents and/or siblings compared to 28 percent of heterosexual respondents. This suggests that our study is capturing abuse perpetrated by parents against adult children. Additionally, 50.7 percent of bisexual respondents and 45.0 percent of lesbian, gay, and other sexuality respondents reported a decrease in household income compared to 42.7 heterosexual respondents. The mediation analysis suggests household income loss slightly mediates the relationship between gender, sexual identity, and experiences with any family violence and verbal abuse during the COVID-19 pandemic. We did not find any statistically significant differences in experiences of family violence between white people and racial minorities, though more research focused on these vulnerable populations is needed.

Our findings have important implications for how victim services and related organizations can support victims and survivors of family violence following the onset of a pandemic and/or economic recession. Organizations should consider maintaining and/ or further developing alternative modes of support for people experiencing violence in their homes, including but not limited to online and text hotlines. As a result of social distancing regulations, many smaller organizations had to adapt service provision to an online platform. National services, such as the National Domestic Violence Hotline, already provided online support options. These services should continue to be an option beyond the duration of the pandemic to increase accessibility. Given findings of increased verbal abuse, robust employee training and client resources related to verbal abuse that is adaptable to a variety of economic crises, such as a global pandemic is also needed. Victim service providers should also be equipped to help victims and survivors navigate unemployment applications and emergent government financial aid resources as new options are made available.

Our findings also demonstrate the importance of workplaces and victim services organizations ensuring their policies are knowledgeable, inclusive, and supportive of sexual minorities. Advocates, legal and judiciary professionals, and healthcare workers should regularly attend LGBTQ related sensitivity training. The Violence Against Women Reauthorization Act (VAWA) of 2021, recently passed by the House, included a new non-discrimination provision to prohibit discrimination against victims of rape, sexual assault, or domestic violence related to both gender and sexual identity. Victim services programs are also guaranteed eligibility for grant funding regardless of the gender and sexual identity of the survivors they serve (H.R., 1620).

\section{Limitations and Future Directions}

This study provides an important glimpse into how the prevalence of family violence has been impacted by the economic and social pressure caused by the COVID-19 pandemic and underscores the importance of further research in this area. There are several limitations.

First, this study is based on a non-representative sample of the United States which limits our ability to make generalized claims, particularly about disparate impacts by race, income, and age. We were surprised the association between women and experiencing family violence was not significant, given the large literature documenting higher rates of family violence among women (Hardesty \& Ogolsky, 2020; Smith et al., 2018). This is likely, at least in part, the result of using a broad definition of family violence that does not measure specific acts or the severity of violent incidents. In their meta-review of the literature regarding intimate partner violence against men, Nowinski and Bowen (2012) suggest that methodologies that rely on less complex measures of family violence, such as the measures used in this study, mask the higher prevalence of family violence perpetrated by men against women, but it also may be capturing family violence among men who identify as LGBTQ. This suggests that our findings for men may largely pertain to gay, bisexual, and other sexual identity men, rather than heterosexual men due to significant interactions. Studies that use incident level details, injury items, and more explicit instructions regarding excluding joking or horseplay demonstrate a higher prevalence of family violence amongst women (Hardesty \& Ogolsky, 2020). Future research on family violence during major health crises and national disasters should employ more nuanced measures of family violence while also capturing how families are navigating contextual factors unique to each event.

Second, respondents were asked to retrospectively compare their experiences with violence before the pandemic with experiences of violence in the preceding 7 days which hinders our ability to establish causality. Our measures of family violence may capture random, acute, or chronic acts of family violence, but we are unable to categorize these experiences based on our measures. Furthermore, data for this study were obtained during April and May 2020, relatively early in the still ongoing COVID-19 pandemic. As the pandemic has continued, economic conditions and social distancing restrictions have also evolved, creating variation in family stressors. It is likely that levels of family violence have fluctuated throughout the pandemic, first in response to new stressors caused by pandemic onset when our study took place (i.e. sudden unemployment, social distancing, etc.) and then adjusting to new and prolonged stressors as the pandemic increased in length (i.e. long term unemployment, illness, etc.). Future work that utilizes a longitudinal or quasi-experimental design will help us understand both the short- and long-term effects of pandemics and economic recessions on the incidence of family violence.

Third, we cannot ascertain who in each household perpetrated violence against respondents. Our measures of violence asked respondents if any person in the household had perpetrated each type of violence against them but did not ask 
them to identify the perpetrator. The barriers survivors face to accessing resources and support vary depending on if the perpetrator is a different sex or same sex intimate partner, a parent, or a roommate. More research is needed to determine how perpetration of family violence during the COVID-19 pandemic varies among intimate partners, parents, and other household members, particularly for children and older adults who are particularly vulnerable to abuse and have access to even fewer resources. Despite these limitations, our study provides additional evidence to support practitioner concerns of increasing family violence during the COVID-19 pandemic and the associated economic recession.

\section{Appendix 1}

Tables 6,7 , and 8

Table 6 Independent variables regressed onto mediator

\begin{tabular}{ll}
\hline & Income loss $(\mathrm{M})$ \\
\hline Women & $1.07(0.92,1.24)$ \\
Sexual Identity & \\
$\quad$ Lesbian/Gay/Other & $1.15(0.85,1.56)$ \\
Bisexual & $1.37^{*}$ \\
& $(1.07,1.74)$ \\
\hline
\end{tabular}

Table 7 Odds ratios mediator regressed onto dependent variables

\begin{tabular}{lllll}
\hline & Any violence & Physical & Verbal & $\begin{array}{l}\text { Restricted } \\
\text { access } \\
\end{array}$ \\
& $(\mathrm{DV})$ & $(\mathrm{DV})$ & $(\mathrm{DV})$ & $(\mathrm{DV})$ \\
\hline Income loss & $1.89^{* * *}$ & 1.47 & $1.77^{* *}$ & 1.58 \\
& $(1.42,2.52)$ & $(0.85,2.54)$ & $(1.29,2.44)$ & $(0.97,2.55)$ \\
\hline
\end{tabular}

Table 8 Decomposition of total effect of gender and sexual identity on experiencing family violence via income loss $(n=2,725)$

\begin{tabular}{|c|c|c|c|c|c|c|c|c|}
\hline & \multicolumn{2}{|c|}{ Any violence } & \multicolumn{2}{|l|}{ Physical } & \multicolumn{2}{|l|}{ Verbal } & \multicolumn{2}{|c|}{ Restricted access } \\
\hline & Coefficient & $\mathrm{z}$ & Coefficient & $\mathrm{z}$ & Coefficient & $\mathrm{z}$ & Coefficient & $\mathrm{z}$ \\
\hline \multicolumn{9}{|l|}{ Coefficients } \\
\hline Total effect & $0.64 * * *$ & 4.32 & 0.38 & 1.36 & $0.57 * * *$ & 3.50 & 0.45 & 1.80 \\
\hline Direct effect & $0.62 * * *$ & 4.27 & 0.37 & 1.31 & $0.55^{* *}$ & 3.36 & 0.45 & 1.81 \\
\hline Indirect effect & 0.01 & 0.71 & 0.01 & 0.62 & 0.02 & 1.92 & 0.00 & -0.08 \\
\hline \multicolumn{9}{|l|}{ Relative Measures } \\
\hline Mediation percentage & $2.22 \%$ & - & $3.44 \%$ & - & 3.83 & - & 0.00 & - \\
\hline
\end{tabular}




\section{Appendix 2}

Table 9

Table 9 Models showing odds of experiencing an increase in family violence $(n=202)$

\begin{tabular}{llll}
\hline & Model 1 & Model 2 & Model 3 \\
\hline Income loss & $1.89^{*}$ & $1.97^{*}$ & $1.99^{*}$ \\
Women (Ref: Men) & & $1.92^{*}$ & $1.94^{*}$ \\
Sexuality (Ref: heterosexual) & & \\
$\quad$ Lesbian/Gay/Other & & 0.73 \\
$\quad$ Bisexual & & 1.16 \\
\hline
\end{tabular}

Acknowledgements This work is supported by the National Science Foundation (NSF) under Grant No. SES-2029963; the University of Maryland Vice President for Research Coronavirus Research Seed Program; and the University of Maryland Prevention Research Center Cooperative Agreement Number U48DP006382 from the Centers for Disease Control and Prevention (CDC). Fish acknowledges support from the Eunice Kennedy Shriver National Center for Child Health and Human Development grant P2CHD041041, Maryland Population Research Center. The content is solely the responsibility of the authors and does not necessarily represent the official views of the NSF, NIH, or CDC.

\section{Declarations}

Conflicts of Interest The authors declare that they have no conflict of interest.

\section{References}

Anderberg, D., Rainer, H., Wadsworth, J., \& Wilson, T. (2016). Unemployment and domestic violence: Theory and evidence. Economic Journal, 126(597), 1947-1979. https://doi.org/10.1111/ecoj.12246.

Arenas-Arroyo, E., Fernandez-Kranz, D., \& Nollenberger, N. (2021). Intimate partner violence under forced cohabitation and economic stress: Evidence from the COVID-19 pandemic. Journal of Public Economics, 194,. https://doi.org/10.1016/j.jpubeco.2020.104350.

Bateman, N., \& Ross, M. (2020). Why has COVID-19 been especially harmful for working women? Brookings Institute. https://www. brookings.edu/essay/why-has-COVID-19-been-especially-harmf ul-for-working-women/.

Breen, R., Karlson, K. B., \& Holm, A. (2013). Total, direct, and indirect effects in logit and probit models. Sociological Methods \& Research, 42(2), 164-191. https://doi.org/10.1177/00491 24113494572.

Breiding, M. J., Smith, S. G., Basile, K. C., Walters, M. L., Chen, J., \& Merrick, M. T. (2014). Prevalence and characteristics of sexual violence, stalking, and intimate partner violence victimization - national intimate partner and sexual violence survey, United States, 2011. Morbidity and Mortality Weekly Report, Centers for Disease Control and Prevention, https://www.cdc. gov/mmwr/preview/mmwrhtml/ss6308a1.htm\#Table2.
Brooks-Gunn, J., Schneider, W., \& Waldfogel, J. (2013). The great recession and the risk for child maltreatment. Child Abuse \& Neglect, 37, 721-729. https://doi.org/10.1016/j.childyouth. 2016.10.016.

Calarco, J. M., Meanwell, E., Anderson, E. M., \& Knopf, A. (2020). "My husband thinks I'm crazy": COVID-19 related conflict in couples with young children. SocArXiv. https://doi.org/10. 31235/osf.io/cpkj6.

Calarco, J. M., Meanwell, E., Anderson, E. M., \& Knopf, A. (2021). By default: The origins of gendered inequalities in pandemic parenting. SocArXiv. https://doi.org/10.31235/osf.io/hgnfs.

Conger, R. D., Elder, G. H., Lorenz, F. O., Conger, K. J., Simons, R. L., Whitbeck, L. B., Huck, S., \& Melby, J. M. (1990). Linking economic hardship to marital quality and instability. Journal of Marriage and the Family, 52(3), 643. https://doi.org/10.2307/352931.

Conger, K. J., Rueter, M. A., \& Conger, R. D. (2000). The role of economic pressure in the lives of parents and their adolescents: The family stress model. In L. J. Crockett \& R. K. Silberiesen (Eds.), Negotiating adolescence in times of social change (pp. 201-223). Cambridge University Press.

Culley, D., \& Sanders, H. (2010). Exploitation and abuse of the elderly during the great recession: A Maine practitioner perspective. Maine Law Review, 62(2), 429-451.

Curry, T. R., Morales, M. C., Zavala, E., \& Hernandez, J. L. (2018). Why is family violence lower among Mexican immigrants? The protective features of Mexican culture. Journal of Family Violence, 33, 171-184. https://doi.org/10.1007/s10896-017-9947-y.

Dixon, E. (2020). Supporting LGBTQ Survivors of Violence During the COVID-19 Pandemic. National Coalition of Anti-Violence Programs. https://avp.org/wp-content/uploads/2020/09/NCAVP COVIDReport_v2.pdf.

Fox, G. L., Benson, M. L., DeMaris, A. A., \& Van Wyk, J. (2002). Economic distress and intimate violence: Testing family stress and resources theories. Journal of Marriage and Family, 64(3), 793-807. https://doi.org/10.1111/j.1741-3737.2002.00793.x.

Fish, J., Salerno, J., Williams, N., Rinderknecht, R. G., Drotning K., Sayer L, \& Doan, Long. (2021). Sexual minority disparities in health and wellbeing as a consequence of the COVID-19 pandemic differ by sexual identity. LGBT Health, 8, 263-272. https:// doi.org/10.1089/lgbt.2020.0489.

Fry, R., Passel, J.S., \& Cohn, D. (2020). A majority of young adults in the U.S. Live with their parents for the first Tiem since the great depression. Pew Research Center, September 4. https:// www.pewresearch.org/fact-tank/2020/09/04/a-majority-of-youngadults-in-the-u-s-live-with-their-parents-for-the-first-time-sincethe-great-depression/.

Gearhart, S., Perez-Patron, M., Hammond, T. A., Goldberg, D. W., Klein, A., \& Horney, J. A. (2018). The impact of natural disasters on domestic violence: An analysis of reports of simple assault in Florida (1999-2007). Violence and Gender, 5(2), 87-92. https:// doi.org/10.1089/vio.2017.0077.

Goodman, J. K., \& Paolacci, G. (2017). Crowdsourcing consumer research. Journal of Consumer Research, 44(1), 196-210. https:// doi.org/10.1093/jcr/ucx047.

Gould, E., \& Shierholz, H. (2020). Not everybody can work from home: Black and Hispanic workers are much less likely to be able to telework. Working Economics Blog, Economic Policy Institute, https://www.epi.org/blog/black-and-hispanic-worke rs-are-much-less-likely-to-be-able-to-work-from-home/.

Hardesty, J. L., \& Ogolsky, B. G. (2020). A socioecological perspective on intimate partner violence research: A decade in review. Journal of Marriage and Family, 82(1), 454-477. https://doi. org/10.1111/jomf.12652.

Hauser, D., Paolacci, G., \& Chandler, J. (2019). Common concerns with MTurk as a participant pool: Evidence and solutions. In F. R. Kardes, P. M. Herr, \& N. Schwarz (Eds.), Handbook of 
research methods in consumer psychology (pp. 319-337). Routledge/Taylor \& Francis Group.

H.R. 1620 - Violence Against Women Act Reauthorization Act of 2021. https://www.congress.gov/bill/117th-congress/house-bill/ $1620 /$ text.

Kalleberg, A. L., \& Vallas, S. P. (2018). Precarious work: Causes, characteristics, and consequences. Research in the Sociology of Work Volume 31. Emerald.

Lanier, C., \& Maume, M. O. (2009). Intimate partner violence and social isolation across the rural/urban divide. Violence against Women, 15(11), 1311-1330. https://doi.org/10.1177/10778 01209346711.

Lattouf, A. (2020). Domestic violence spikes during coronavirus as families trapped at home. https://10daily.com.au/news/australia/ a200326zyjkh/domestic-violence-spikes-during-coronavirus-asfamilies-trapped-at-home-20200327. Accessed March 28, 2020.

Lucero, J. L., Lim, S., \& Santiago, A. M. (2016). Changes in economic hardship and intimate partner violence: A family stress framework. Journal of Family and Economic Issues, 37(3), 395-406. https://doi.org/10.1007/s10834-016-9488-1.

McGeough, B. L., \& Sterzing, P. R. (2018). A systematic review of family victimization experiences among sexual minority youth. Journal of Primary Prevention, 39(5), 491-528. https://doi.org/ 10.1007/s10935-018-0523-x.

Modestino, A. S. (2020). Coronavirus child-care crisis will set women back a generation. Washington Post, June 29. https:// www.washingtonpost.com/us-policy/2020/07/29/childcareremote-learning-women-employment/.

Morgan, R. E., \& Truman, J. L. (2020). Criminal Victimization, 2019. Bureau of Justice Statistics.

National Domestic Violence Hotline. (2020). COVID-19 Special Report. https://www.thehotline.org/wp-content/uploads/sites/3/ 2020/06/2005-TheHotline-COVID19-report_final.pdf.

Nowinski, S. N., \& Bowen, E. (2012). Partner violence against heterosexual and gay men: Prevalence and correlates. Aggression and Violent Behavior, 17(1), 36-52. https://doi.org/10.1016/j. avb.2011.09.005.

Peer, E., Vosgerau, J., \& Acquisti, A. (2014). Reputation as a sufficient condition for data quality on amazon mechanical Turk. Behavior Research Methods, 46(4), 1023-1031. https://doi.org/ 10.3758/s13428-013-0434-y.

Peer, E., Brandimarte, L., Samat, S., \& Acquisti, A. (2017). Beyond the Turk: Alternative platforms for crowdsourcing behavioral research. Journal of Experimental Social Psychology, 70, 153163. https://doi.org/10.1016/j.jesp.2017.01.006.

Peterman, A., Potts, A., O’Donnell, M., Thompson, K., Shah, N., Oertelt-Prigione, S., \& Van Gelder, N. (2020). Pandemics and Violence Against Women and Children. CGD Working Paper 528. Center for Global Development.

Prime, H., Wade, M., \& Browne, D. T. (2020). Risk and resilience in family well-being during the COVID-19 pandemic. American Psychologist Online. https://doi.org/10.1037/amp0000660.

Renzetti, C .M. (2009). Economic stress and domestic violence. VAWnet.org, 1-15.

Rezaeian, M. (2013). The association between natural disasters and violence: A systematic review of the literature and a call for more epidemiological studies. Journal of Research in Medical Sciences, 18(12), 1103. https://www.ncbi.nlm.nih.gov/pmc/articles/PMC39 08534/-1107.
Ruggles, S. (2015). Patriarchy, power, and pay: The transformation of american families, 1800-2015. Demography, 52(6), 1797-1823. https://doi.org/10.1007/s13524-015-0440-z.

Salerno J. P., Doan L, Sayer L., Drotning K., Rinderknecht R. G., \& Fish J. N. (2021). Changes in mental health and wellbeing are associated with living arrangements with parents during COVID19 among sexual minority young persons in the U.S. Psychology of Sexual Orientation and Gender Diversity 1-7. https://doi.org/ $10.1037 / \mathrm{sgd} 0000520$

Schneider, D., Harknett, K., \& McLanahan, S. (2016). Intimate partner violence in the great recession. Demography, 53, 471-505. https:// doi.org/10.1007/s13524-016-0462-1.

Smith, S. G., Zhang, X., Basile, K. C., Merrick, M. T., Wang, J., Kresnow, M., \& Chen, J. (2018). National Intimate Partner and Sexual Violence Survey: 2015 Data Brief-Updated Release. National Center for Injury Prevention and Control, Centers for Disease Control and Prevention.

Stark, E. (2007). Coercive control: The entrapment of women in personal life. Oxford University.

Stephenson, R. and Finneran, C. (2013). The IPV-GBM Scale: A new scale to measure intimate partner violence among gay and bisexual men. PLOS ONE, 8(6). https://doi.org/10.1371/journal. pone.0062592.

Tillery, B., Ray, A., Cruz, E., \& Waters, E. (2018). Lesbian, gay, bisexual, transgender, queer and HIV-affected hate and intimate partner violence in 2017. National Coalition of Anti-Violence Programs.

Usher, K., Bhullar, N., Durkin, J., Gyamfi, N., \& Jackson, D. (2020). Family violence and COVID-19: Increased vulnerability and reduced options for support. International Journal of Mental Health Nursing, 23, 549-552. https://doi.org/10.1111/inm.12735.

Wako, E., Elliott, L., De Jesus, S., Zotti, M. E., Swahn, M. H., \& Beltrami, J. (2015). Conflict, displacement, and IPV: Findings from two Congolese refugee camps in Rwanda. Violence against Women, 21(9), 1087-1101. https://doi.org/10.1177/1077801215590669.

Walters, M. L., Chen, J., \& Breiding, M. J. (2013). The National Intimate Partner and Sexual Violence Survey (NISVS): 2010 findings on victimization by sexual orientation. National Center for Prevention and Control Centers for Disease Control and Prevention, https:// www.cdc.gov/ViolencePrevention/pdf/NISVS_SOfindings.pdf.

Wanqing, Z. (2020). Domestic violence cases surge during COVID19 epidemic. https://www.sixthtone.com/news/1005253/domes tic-violence-cases-surge-during-COVID-19-epidemic.

Whittington, C., Hadfield, K., \& Calderón, C. (2020). The lives and livelihoods of many in the LGBTQ+ community are at risk amidst COVID-19 crisis. Human Rights Campaign Foundation, 1-7.

Winter, N., Burleigh, T., Kennedy, R., \& Clifford, S. (2019). A simplified protocol to screen out VPS and international respondents using qualtrics. SSRN Electronic Journal. https://doi.org/10.2139/ ssrn. 3327274 .

Zadnik, E., Sabina, C., \& Cuevas, C. A. (2014). Violence against Latinas: The effects of undocumented status on rates of victimization and help-seeking. Journal of Interpersonal Violence, 31, 11411153. https://doi.org/10.1177/0886260514564062.

Zhang, H. (2020). The influence of the ongoing COVID-19 pandemic on family violence in China. Journal of Family Violence. https:// doi.org/10.1007/s10896-020-00196-8.

Publisher's Note Springer Nature remains neutral with regard to jurisdictional claims in published maps and institutional affiliations. 